\title{
In silico characterization of antifreeze proteins using computational tools and servers
}

\author{
K SIVAKUMAR, $^{1, *}$ S BALAJI ${ }^{1}$ and GANGARADHAKRISHNAN ${ }^{2}$ \\ ${ }^{1}$ Department of Chemistry, Sri Chandrasekharendra Saraswathi Viswa Maha Vidyalaya \\ (Deemed University), Enathur, Kanchipuram 631561 \\ ${ }^{2}$ EXCEL and Polymer Science Labs, Central Leather Research Institute, Adyar, Chennai 600020 \\ e-mail: shivamk25@yahoo.co.in
}

MS received 13 June 2007; accepted 9 August 2007

\begin{abstract}
In this paper, seventeen different fish Antifreeze Proteins (AFPs) retrieved from Swiss-Prot database are analysed and characterized using In silico tools. Primary structure analysis shows that most of the AFPs are hydrophobic in nature due to the high content of non-polar residues. The presence of 11 cysteines in the rainbow smelt fish and sea raven fish AFPs infer that these proteins may form disulphide (SS) bonds, which are regarded as a positive factor for stability. The aliphatic index computed by ExPasy's ProtParam infers that AFPs may be stable for a wide range of temperature. Secondary structure analysis shows that most of the fish AFPs have predominant $\alpha$-helical structures and rest of the AFPs have mixed secondary structure. The very high coil structural content of rainbow smelt fish and sea raven fish AFPs are due to the rich content of more flexible glycine and hydrophobic proline amino acids. Proline has a special property of creating kinks in polypetide chains and disrupting ordered secondary structure. SOSUI server predicts one transmembrane region in winter flounder fish and atlantic cod and two transmembrane regions in yellowtail flounder fish AFP. The predicted transmembrane regions were visualized and analysed using helical wheel plots generated by EMBOSS pepwheel tool. The presence of disulphide (SS) bonds in the AFPs Q01758 and P05140 are predicted by CYS_REC tool and also identified from the three-dimensional structure using Rasmol tool. The disulphide bonds identified from the three-dimensional structure using the Rasmol tool might be correct as the evaluation parameters are within the acceptable limits for the modelled 3D structures.
\end{abstract}

Keywords. Antifreeze proteins; computational analysis; disulphide bridges; homology modelling; proteomics tools.

\section{Introduction}

Computational packages and online servers are the current tools used in the protein sequence analysis and characterization. ${ }^{1}$ The physicochemical and the structural properties of the proteins are well understood with the use of computational tools. Today, number of computational tools has been developed for making predictions regarding the identification and structure prediction of proteins. The statistics about a protein sequence such as number of amino acid, sequence length, and the physico-chemical properties of a proteins such as molecular weight, atomic composition, extinction coefficient, GRAVY, aliphatic index, instability index, etc. can be computed by computational tools for the prediction and characterization of protein structure. The amino acid se-

\footnotetext{
*For correspondence
}

quence provides most of the information required for determining and characterizing the molecule's function, physical and chemical properties. Sequence analysis and physicochemical characterization of proteins using biocomputation tools have been done by many researches and reported. ${ }^{2-8}$ Antifreeze Proteins (AFPs) were first identified in fishes. Antifreeze proteins resist ice crystal growth and prevent cellular damage in the organisms due to freezing. AFP molecules have a strong affinity for ice due to their structure. AFPs protect the organism from freezing at temperature below $1^{\circ} \mathrm{C}$ by interacting with small ice crystals and inhibit their growth through an adsorption-inhibition mechanism. ${ }^{9}$ Many researchers have purified and analysed macromolecular antifreeze proteins from a number of plants, fishes and insects. To date researches have identified five different AFPs from fish and they are classified as Antifreeze Glycoproteins and Antifreeze proteins Type I, Type II, 
Type III and Type IV based on their properties, moleular weight and structure. ${ }^{10}$ AFPs are highly useful in the preservation techniques because of their recrystallization inhibition property. ${ }^{11}$ AFPs have potential applications in agriculture for protecting crops from freezing, in maintaining the texture in frozen foods and for producing cold-hardy plants using transgenic technology. AFPs are used in the cryosurgery for the low temperature preservation of cells, tissues and organs. ${ }^{12}$ Chao et $a l^{13}$ have reported the relative efficacy of AFP types I, II and III in protecting the red blood cells. Numerous structure and function studies have been reported from time to time from all over the world. ${ }^{14-18}$ However, physico-chemical characterization of antifreeze protein has not been done so far. In this paper, we report the In silico analysis and characterization studies on 17 AFPs of various fishes.

\section{Materials and methods}

\subsection{Antifreeze protein sequences}

Antifreeze protein sequences were retrieved from the manually curated public protein database SwissProt. ${ }^{19}$ Swiss-Prot is scanned for the key word antifreeze. The search result yielded 39 antifreeze protein sequences of 17 fishes. From this, we have retrieved 17 different fish AFPs (i.e. one antifreeze protein is chosen from each type of fish) by random selection and have organized a non-redundant data set (table 1). The AFPs were retrieved in FASTA format and used for analysis.

\subsection{Computational tools and servers}

The amino acid composition (table 2) of AFP sequences were computed using the tool CLC free Workbench. ${ }^{20}$ Percentages of hydrophobic and hydrophilic residues were calculated from the primary structure analysis results and tabulated in table 3 . The physico-chemical parameters, theoretical isoelectric point (pI), molecular weight, total number of positive and negative residues, extinction coefficient, ${ }^{21}$ half-life, ${ }^{22-25}$ instability index, ${ }^{26}$ aliphatic inde ${ }^{27}$ and grand average hydrophathy ${ }^{28}$ (GRAVY) were computed using the Expasy's ProtParam (http://us.expasy.org/tools/ protparam.html) prediction server and tabulated in table 4. The tools SOPM, SOPMA ${ }^{29}$ and Secondary Structural Content Prediction (SSCP method-I) server ${ }^{30}$ were used for the secondary structure prediction. The SOSUI ${ }^{31}$ server performed the identification of transmembrane regions (table 5). The predicted transmembrane helices were visualized and analysed using helical wheel plots (figure 2) generated by the program Pepwheel ${ }^{32}$ included in the EMBOSS 2.7 suite. The presence of disulphide bridges (SS bonds) in AFPs Q01758 and P05140 is predicted by two methods. The first method involves the prediction of SS bonds using the primary structure (protein sequence data) by the tool CYS_REC. ${ }^{33}$ CYS_REC identifies the positions of cysteines, total number of cysteines present and predicts the most probable SS bond pattern of pairs in the protein sequence. The second method involves the visualization and identification of SS bonds using the three-dimensional

Table 1. Antifreeze protein sequences retrieved from Swiss-Prot database.

\begin{tabular}{lll}
\hline $\begin{array}{l}\text { Accession } \\
\text { number }\end{array}$ & \multicolumn{1}{c}{ Sequence description } & \multicolumn{1}{c}{ Organism } \\
\hline P20617 & Antifreeze peptide GS-8 & Grubby sculpin (Myoxocephalus aenaeus) \\
P04368 & Antifreeze peptide SS-8 & Shorthorn sculpin (Myoxocephalus scorpius) \\
P80961 & Antifreeze protein LS-12 & Longhorn sculpin (Myoxocephalus octodecimspinosis) \\
P24028 & Antifreeze protein LP & Canadian eelpout (Lycodes polaris) \\
P12101 & Antifreeze peptide AB2 & Antarctic eelpout (Pachycara brachycephalum) \\
P35751 & Antifreeze peptide RD1 & Antarctic eelpout (Rhigophila dearborni) \\
P07457 & Antifreeze protein SP1-C & Ocean pout (Macrozoarces americanus) \\
P12417 & Antifreeze protein type III & Atlantic wolfish (Anarhichas lupus) \\
Q01758 & Type II antifreeze protein & Rainbow smelt (Osmerus mordax) \\
P05140 & Type II antifreeze protein & Sea raven (Hemitripterus americanus) \\
P04002 & Antifreeze protein A & Winter flouonder (Pseudopleuronectes americanus) \\
P09031 & Antifreeze protein & Yellowtail flounder (Limanda ferruginea) \\
Q8J137 & Type-4 ice-structuring protein & Japanese flounder (Paralichthys olivaceus) \\
Q56TU0 & Type-4 ice-structuring protein precursor & Atlantic cod (Gadus morhua) \\
P11920 & Antifreeze glycoprotein 7R & Saffron cod (Eleginus gracilis) \\
P02732 & Antifreeze glycoprotein 3 & Bald rockcod (Pagothenia borchgrevinki) \\
P24856 & Antifreeze glycopeptide polyprotein & Black rockcod (Notothenia coriiceps neglecta) \\
\hline
\end{tabular}




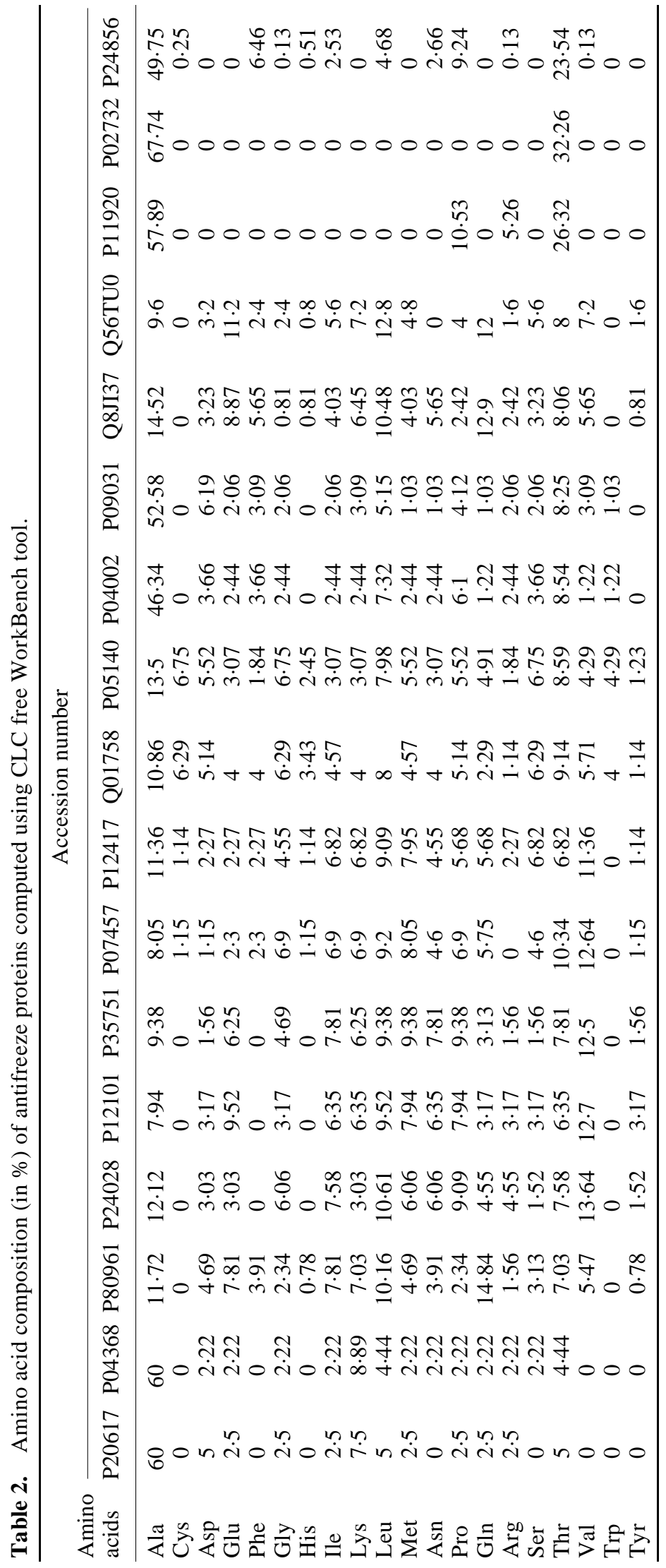


Table 3. Hydrophilic and hydrophobic residues content.

\begin{tabular}{lccl}
\hline $\begin{array}{l}\text { Accession } \\
\text { number }\end{array}$ & $\begin{array}{c}\text { Percentage of } \\
\text { hydrophobic residues }\end{array}$ & $\begin{array}{c}\text { Percentage of } \\
\text { hydrophilic residues }\end{array}$ & $\begin{array}{c}\text { Net hydrophobic } \\
\text { residues content }\end{array}$ \\
\hline P20617 & 70 & 25 & Very high \\
P04368 & $68 \cdot 88$ & $26 \cdot 65$ & Very high \\
P80961 & $43 \cdot 76$ & 51.56 & Low \\
P24028 & $50 \cdot 01$ & $34 \cdot 87$ & High \\
P12101 & $44 \cdot 45$ & $44 \cdot 42$ & High \\
P35751 & $48 \cdot 45$ & $37 \cdot 49$ & High \\
P07457 & $56 \cdot 32$ & $43 \cdot 67$ & High \\
P12417 & $48 \cdot 85$ & $39 \cdot 78$ & - \\
Q01758 & $41 \cdot 71$ & $40 \cdot 57$ & Very high \\
P05140 & $40 \cdot 49$ & $40 \cdot 5$ & Very high \\
P04002 & $64 \cdot 64$ & $26 \cdot 84$ & Low \\
P09031 & $68 \cdot 03$ & $25 \cdot 77$ & Low \\
Q8JI37 & $45 \cdot 96$ & $54 \cdot 03$ & High \\
Q56TU0 & $46 \cdot 4$ & $53 \cdot 6$ & High \\
P11920 & $57 \cdot 89$ & $42 \cdot 10$ & High \\
P02732 & $67 \cdot 74$ & $32 \cdot 25$ & \\
P24856 & $63 \cdot 92$ & $36 \cdot 07$ & \\
\hline
\end{tabular}

Table 4. Parameters computed using Expasy's ProtParam tool.

\begin{tabular}{lcccrrrrrr}
\hline $\begin{array}{l}\text { Accession } \\
\text { number }\end{array}$ & $\begin{array}{c}\text { Sequence } \\
\text { length }\end{array}$ & M. wt & pI & $-\mathrm{R}$ & $+\mathrm{R}$ & $\mathrm{EC}$ & $\mathrm{II}$ & $\mathrm{AI}$ & GRAVY \\
\hline P20617 & 40 & 3579 & $8 \cdot 25$ & 3 & 4 & $\mathrm{Nil}$ & $10 \cdot 56$ & $89 \cdot 25$ & $0 \cdot 59$ \\
P04368 & 45 & $4006 \cdot 5$ & 10 & 2 & 5 & Nil & $7 \cdot 16$ & 86 & $0 \cdot 54$ \\
P80961 & 128 & $14377 \cdot 5$ & $4 \cdot 8$ & 16 & 11 & 1280 & $41 \cdot 21$ & $97 \cdot 66$ & $-0 \cdot 218$ \\
P24028 & 66 & $6982 \cdot 3$ & $8 \cdot 5$ & 4 & 5 & 1280 & $26 \cdot 31$ & $122 \cdot 58$ & $0 \cdot 489$ \\
P12101 & 63 & $7001 \cdot 2$ & $4 \cdot 96$ & 8 & 6 & 2560 & $24 \cdot 2$ & $106 \cdot 67$ & $0 \cdot 056$ \\
P35751 & 64 & $6906 \cdot 3$ & $6 \cdot 39$ & 5 & 5 & 1280 & $17 \cdot 25$ & $112 \cdot 66$ & $0 \cdot 353$ \\
P07457 & 87 & 9229 & $9 \cdot 36$ & 3 & 6 & 1490 & $21 \cdot 29$ & $107 \cdot 47$ & $0 \cdot 531$ \\
P12417 & 88 & $9430 \cdot 3$ & $9 \cdot 65$ & 4 & 8 & 1280 & $30 \cdot 24$ & $106 \cdot 36$ & $0 \cdot 43$ \\
Q01758 & 175 & $19053 \cdot 9$ & $5 \cdot 16$ & 16 & 9 & 42990 & $33 \cdot 3$ & $76 \cdot 46$ & $0 \cdot 171$ \\
P05140 & 163 & 17509 & $4 \cdot 93$ & 14 & 8 & 42990 & $36 \cdot 05$ & $69 \cdot 02$ & $0 \cdot 045$ \\
P04002 & 82 & $7710 \cdot 7$ & $4 \cdot 86$ & 5 & 4 & 5690 & $24 \cdot 69$ & $87 \cdot 93$ & $0 \cdot 668$ \\
P09031 & 97 & $8864 \cdot 9$ & $4 \cdot 41$ & 8 & 5 & 5690 & $10 \cdot 56$ & $89 \cdot 69$ & $0 \cdot 739$ \\
Q8JI37 & 124 & 12946 & $4 \cdot 96$ & 15 & 11 & 1490 & $34 \cdot 42$ & $87 \cdot 50$ & $-0 \cdot 281$ \\
Q56TU0 & 125 & $13991 \cdot 2$ & $4 \cdot 68$ & 18 & 11 & 2980 & $47 \cdot 4$ & $102 \cdot 24$ & $-0 \cdot 126$ \\
P11920 & 19 & $1655 \cdot 8$ & $9 \cdot 79$ & 0 & 1 & Nil & $29 \cdot 75$ & $57 \cdot 89$ & $0 \cdot 453$ \\
P02732 & 31 & $2521 \cdot 7$ & $5 \cdot 57$ & 0 & 0 & Nil & $9 \cdot 68$ & $67 \cdot 74$ & $0 \cdot 994$ \\
P24856 & 790 & $71266 \cdot 5$ & $8 \cdot 08$ & 0 & 1 & 125 & $24 \cdot 41$ & $78 \cdot 25$ & $0 \cdot 952$ \\
\hline
\end{tabular}

M. wt., Molecular weight; pI, Isoelectric point; $-\mathrm{R}$, Number of negative residues; +R, Number of positive residues; EC, Extinction coefficient at $280 \mathrm{~nm}$; II, Instability index; AI, Aliphatic index; GRAVY, Grand Average Hydropathy.

structure of protein (3D coordinates data). The 3D structure of AFPs Q01758 and P05140 were generated by homology modelling using Esypred ${ }^{34}$ server. The similar 3D structures (for the AFPs Q01758 and P05140 sequences) in the Protein Data bank (www.rscb.org) were identified by the BLASTP analysis (http://www.ncbi.nlm.nih.gov:80/BLAST/). The modelled 3D structures were evaluated using the online servers Rampage, ${ }^{35}$ ProQ $^{36}$ (Protein Quality server) and $\mathrm{CE}^{37}$ (Combinatorial Extension). The tool Rasmol (http://openrasmol.org/) is used to visualize the modelled 3D structures and to identify the SS bonds. The three-dimensional structures of AFPs Q01758 and P05140 modelled using the PDB template 2AFP_A are shown in figures 3 and 4 respectively. The five most probable SS bond pattern of 


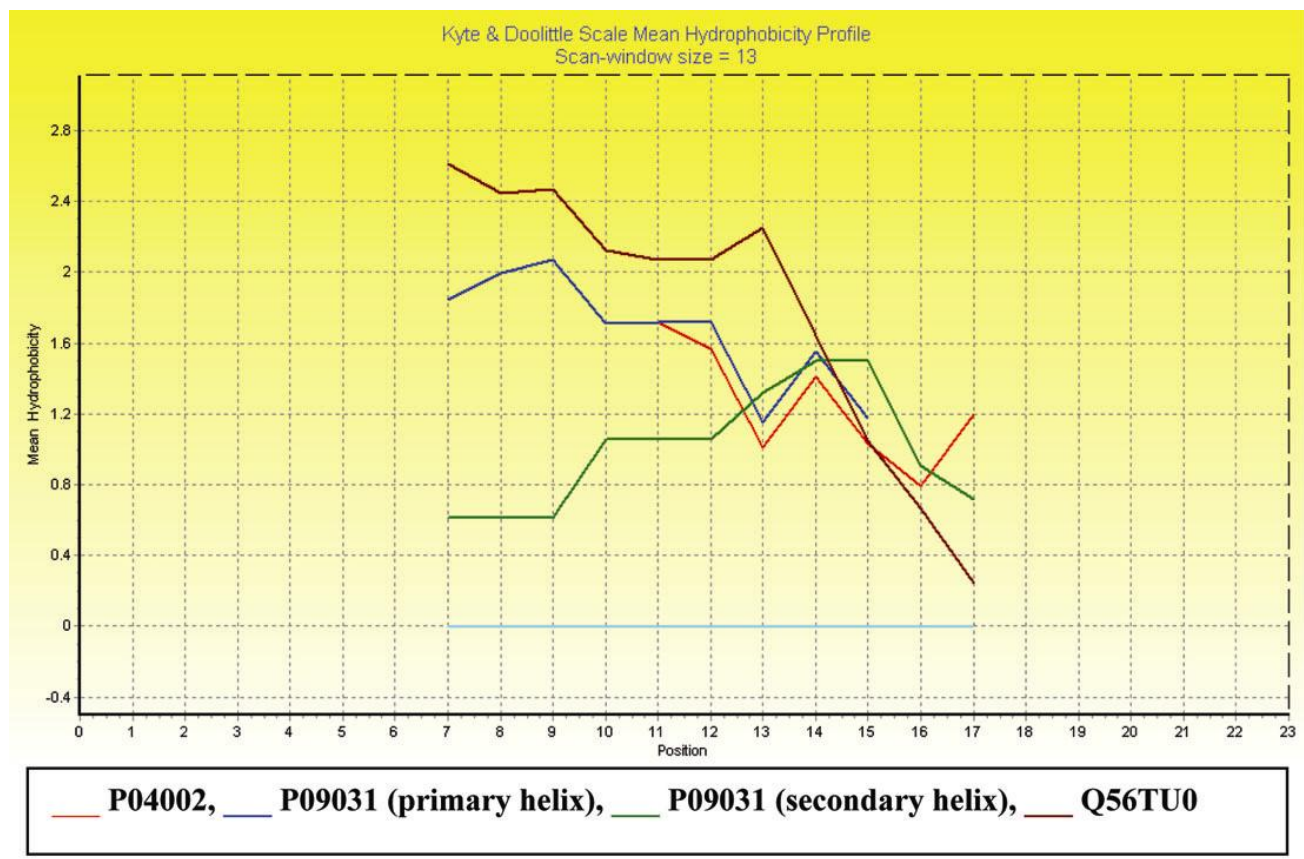

Figure 1. Kyte and Doolittle mean hydrophobicity profile computed for the transmembrane regions of AFPs P04002, P09031 (primary and secondary helices) and Q56TU0.

Table 5. Transmembrane regions identified by SOSUI server.

\begin{tabular}{lllc}
\hline Accession number & \multicolumn{1}{c}{ Transmembrane region } & \multicolumn{1}{c}{ Type } & Length \\
\hline P04002 & MALSLFTVGQLIFLFWTMRITEA & Primary & 23 \\
P09031 & MALSLFTVGQLIFLFWTLRIT & Primary & 21 \\
& AAKAAPAAVADPAAAAAAAVADT & Secondary & 23 \\
Q56TU0 & YTLIAAIVVLALAQGTLAVEQSP & Primary & 23 \\
\hline
\end{tabular}

Table 6. Disulphide (SS) bond pattern of pairs predicted, by CYS_REC (using primary structure) and identified by Rasmol (using 3D structure modelled).

\begin{tabular}{lll}
\hline Accession number & \multicolumn{1}{c}{ CYS_REC } & \multicolumn{1}{c}{ RasMol } \\
\hline Q01758 & Cys38-Cys49 & Cys38-Cys49 \\
& Cys66-Cys135 & Cys66-Cys159 \\
& Cys103-Cys145 & Cys135-Cys151 \\
& Cys123-Cys134 & Cys103-Cys134 \\
& Cys151-Cys159 & Cys123-Cys145 \\
P05140 & Cys41-Cys52 & Cys41-Cys52 \\
& Cys69-Cys159 & Cys69-Cys159 \\
& Cys103-Cys134 & Cys103-Cys134 \\
& Cys123-Cys145 & Cys123-Cys145 \\
& Cys135-Cys151 & Cys135-Cys151 \\
\hline
\end{tabular}

pairs predicted by CYS_REC tool and the positions of SS bonds identified using Rasmol tool in the AFPs Q01758 and P05140 are shown in table 6.

\section{Results and discussion}

The results of primary structure analysis suggest that most of the AFPs are hydrophobic in nature due to the presence of high non-polar residues content (tables 2 and 3). The presence of 11 Cys residues in AFPs Q01758 (6.29\% of Cys) (rainbow smelt fish) and P05140 (6.75\% of Cys) (sea raven fish) indicates the presence of disulphide bridges (SS bonds) in these AFPs. Moreover, the primary structure analysis suggests that the AFPs P20617, P04368, P11920 and P02732 have no aromatic residues (Tyr, Phe and Trp). The average molecular weight of AFPs calculated is $12766 \mathrm{Da}$. Isoelectric point (pI) is the $\mathrm{pH}$ at which the surface of protein is covered with charge but net charge of the protein is zero. At pI proteins are stable and compact. The computed pI value of P80961, P12101, P35751, Q01758, P05140, P04002, P09031, 
Q8JI37 and Q56TU0 ( $\mathrm{pI}<7)$ indicates that these AFPs are acidic and the pI of P20617, P04368, P24028, P12417, P07457, P11920 and P24856 ( $\mathrm{pI}>7$ ) reveals that these are basic in character. The computed isolelectric point (pI) will be useful for developing buffer systems for purification by isoelectric focusing method. Although Expasy's ProtParam computes the extinction coefficient for a range of (276, 278, 279, 280 and $282 \mathrm{~nm}$ ) wavelength, $280 \mathrm{~nm}$ is favoured because proteins absorb strongly there while other substances commonly in protein solutions do not. Extinction coefficient of AFPs at $280 \mathrm{~nm}$ is ranging from 1280 to $42990 \mathrm{M}^{-1} \mathrm{~cm}^{-1}$ with respect to the concentration of Cys, Trp and Tyr. The high extinction coefficient of Q01758 and P05140 indicates presence of high concentration of Cys, Trp and

Table 7. PDB templates (first 2 hits with maximum \% identity) obtained using BLASTP search against the Protein Data Bank.

\begin{tabular}{lc}
\hline Accession number & PDB code \\
\hline Q01758 & 2AFP_A \\
& 1XAR_B \\
P05140 & 2AFP_A \\
& 1QDD_A \\
\hline
\end{tabular}

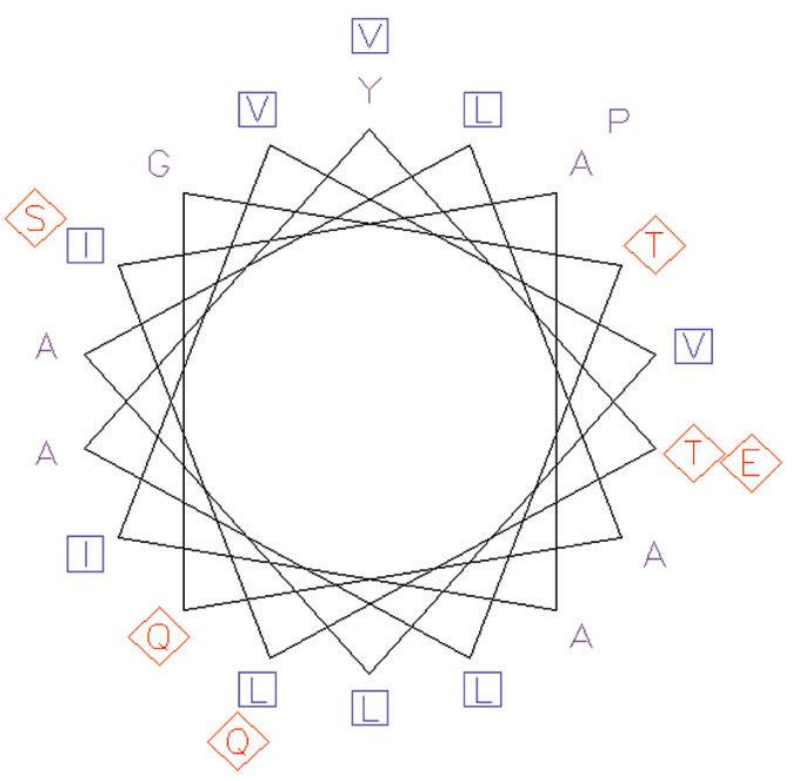

Figure 2. Helical wheel representation of predicted helix of Q56TU0 (Atlantic cod fish) AFP. Hydrophobic residues (V, L, I) are represented as blue squares and violet letters $(A, G, P, Y)$, polar residues $(E, Q, S, T)$ as red diamonds.
Tyr. Expasy's ProtParam computes no value for P20617, P04368, P11920 and P02732 because it has no Cys, Trp or Tyr. This indicates that these AFPs cannot be analysed using UV spectral methods. The computed protein concentration and extinction coefficients help in the quantitative study of proteinprotein and protein-ligand interactions in solution. The biocomputed half-life of most of the AFPs is greater than $20 \mathrm{~h}$. The half-life is only $4.4 \mathrm{~h}$ for P11920, P02732 and 3 min for AFPs P24028 and P35751. On the basis of instability index Expasy's ProtParam classifies the P80961 (Longhorn Sculphin fish) and Q56TU0 (Atlantic cod) AFPs as unstable (Instability index $>40$ ) and other AFPs as stable (Instability index <40). The aliphatic index (AI) which is defined as the relative volume of a protein occupied by aliphatic side chains ( $\mathrm{A}, \mathrm{V}, \mathrm{I}$ and $\mathrm{L})$ is regarded as a positive factor for the increase of thermal stability of globular proteins. The lower thermal stability of P05140, P11920 and P02732 is indicative of a more flexible structure when compared to other AFPs (table 4). The very high aliphatic index of all AFPs infers that AFPs may be stable for a wide range of temperature. Grand Average hydropathy (GRAVY) Index of AFPs are ranging from $-0 \cdot 1$ to $0 \cdot 9$. The very low GRAVY index of AFPs P80961, Q8JI37 and Q56TU0 infers that these AFPs could result in a better interaction with water. The secondary structure predicted with the help of programs SOPM and SOPMA (data not shown) infers that the AFPs P20617, P04368, P80961 (Sculphin fishes),

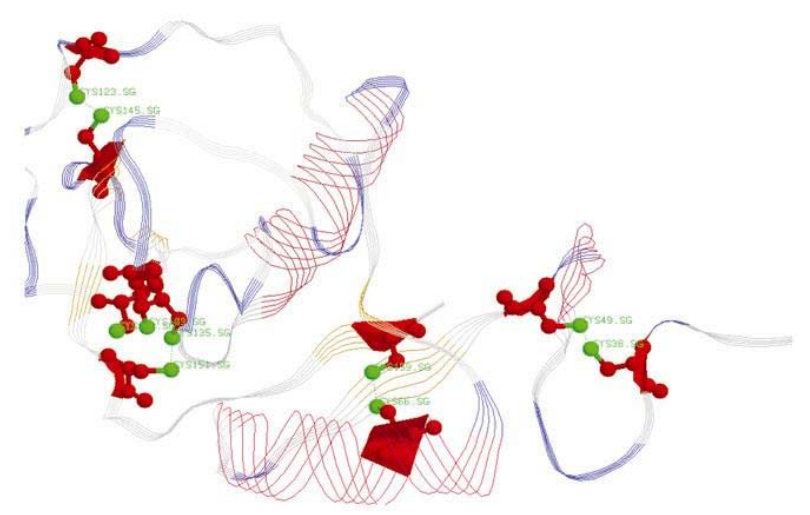

Figure 3. RasMol (strands) representation of the homology modelled 3D structure of antifreeze protein Q01758 (using PDB template 2AFP_A). The 10 cysteines are shown as ball and stick models (red). The sulphur atoms present in cysteines and the SS bonds (dotted lines) are shown in green colour. One unpaired cysteine is not shown. 
Table 8. Validation parameters computed for the built 3D structures of targets Q01758 and P05140.

\begin{tabular}{lccccc}
\hline & & RamPage & & \multicolumn{2}{c}{ ProQ } \\
\cline { 4 - 6 } Target & Template (PDB) codes & $\begin{array}{c}\text { Percentage of residues } \\
\text { in favoured region }\end{array}$ & $\begin{array}{c}\text { CE } \\
\text { RMSD }(\AA)\end{array}$ & LG Score & Maxsub \\
\hline Q01758 & 2AFP_A & 82 & $0 \cdot 5$ & 1.464 & $0 \cdot 245$ \\
& 1XAR_B & 65 & $2 \cdot 0$ & $0 \cdot 9$ & $0 \cdot 063$ \\
P05140 & 2AFP_A & $81 \cdot 1$ & $0 \cdot 5$ & $1 \cdot 604$ & $0 \cdot 2$ \\
& 1QDD_A & 52 & $1 \cdot 8$ & $1 \cdot 3$ & $0 \cdot 12$ \\
\hline
\end{tabular}

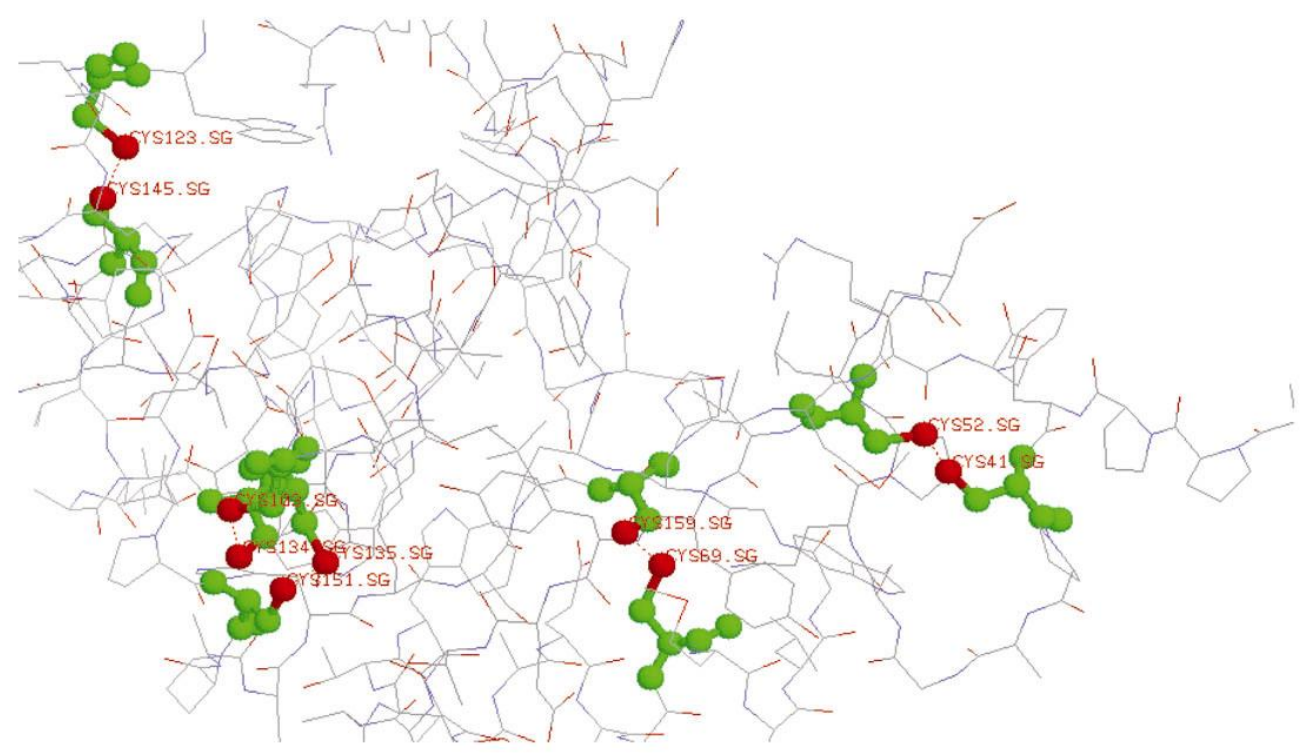

Figure 4. RasMol (wireframe diagram) representation of the homology modelled 3D structure of antifreeze protein P05140 (using PDB template 2AFP_A). The 10 cysteines are shown as ball and stick models (green). The sulphur atoms present in cysteines and the SS bonds (dotted lines) are shown in red colour. One unpaired cysteine is not shown.

P04002, P09031, Q8JI37 (Flounder fishes) and Q56TU0, P11920, P02732, P24856 (Cod fishes) have rich alanine content and mostly $\alpha$-helices. AFPs P24028, P12101, P35751 (eelpout fishes), P12417 (Atlantic wolffish) Q01758 (rainbow smelt) P05140 (sea raven) and P07457(Ocean pout) have mixed secondary structure, i.e. $\alpha$-helices $\beta$-strands and coils. The very high coil structural content of rainbow smelt fish (47.1\%) and sea raven fish (50.4\%) AFPs are due to the rich content of more flexible glycine and hydrophobic proline amino acids. Proline has a special property of creating kinks in polypetide chains and disrupting ordered secondary structure. The server SOSUI classifies the flounder fish AFPs P04002, P09031 and Atlantic cod fish AFP Q56TU0 as membrane protein and other AFPs as soluble pro- teins. SOSUI server has identified one transmembrane region in P04002 and Q56TU0 and two transmembrane regions in P09031. The transmembrane regions and their length are tabulated in table 5. The transmemebrane regions are rich in hydrophobic aminoacids and it is also well documented by Kyte and Dolittle mean hydrophobicity profile (figure 1) in which all the points are above the 0.0 line. The helix of Q56TU0 visualized using EMBOSS pepwheel is shown in figure 2. The tool CYS_REC recognizes the presence of 11 Cysteines in AFPs Q01758 and P05140 sequences and predicted five most probable SS bond pattern of pairs (as discussed in the primary structure analysis) in both of the proteins. The positions of five most probable SS bonds predicted by CYS_REC and the five SS bonds identi- 
Table 9. Criteria for a good (model) 3D structure.

\begin{tabular}{lcccl}
\hline \multirow{2}{*}{$\begin{array}{l}\text { RamPage } \\
\text { Percentage of residues }\end{array}$} & CE & \multicolumn{2}{c}{ ProQ } & \\
\cline { 3 - 4 } in favoured region & RMSD $(\AA)$ & LG score & Maxsub & Quality of the model \\
\hline 98 & $<2$ & $>1.5$ & $>0 \cdot 1$ & Fairly good model \\
& & $>2.5$ & $>0.5$ & Very good model \\
& & $>4$ & $>0.8$ & Extremely good model \\
\hline
\end{tabular}

fied using Rasmol in the AFPs Q01758 and P05140 are shown in table 6 . The three-dimensional structures of AFPs Q01758 and P05140 were modelled using various PDB templates (table 7) selected from the hits obtained through the BLASTP analysis and the modelled structures were evaluated. According to evaluation analysis, the Ramachandran plot and other parameters (table 8) were within the standard acceptable limits for the $3 \mathrm{D}$ structures modelled using the PDB template 2AFP_A for both of the (target) proteins. Criteria for a good 3D structure is given in table 9. The cysteines and the SS bonds identified using the three-dimensional structures of AFPs Q01758 and P05140 are shown in figures 3 and 4 respectively. In the case of AFP Q01758 the four SS bond positions Cys66-Cys135, Cys103Cys145, Cys123-Cys134 and Cys151-Cys159 predicted by CYS_REC are not correlating with the SS bond positions Cys66-Cys159, Cys135-Cys151, Cys103-Cys134 and Cys123-Cys145 identified using Rasmol tool. We speculate that the SS bonds predicted from the primary structure (protein sequence) using CYS_REC tool might not be correct and the SS bonds identified from the three-dimensional structure (3D coordinates) using the Rasmol tool might be correct. The ten cysteines and five SS bonds present in the AFPs Q01758 and P05140 are shown in figures 3 and 4 . The one unpaired cysteine in both the proteins is not shown in the figures.

\section{Conclusions}

Seventeen fish antifreeze proteins have been chosen mainly to study their physico-chemical properties, primary and secondary structures by using computational tools and servers. Primary structure analysis reveals that most of the AFPs under study are hydrophobic in nature and two of them contain disulphide linkages. Physico-chemical characterization studies give a good idea about the properties such as PI, EC, AI, GRAVY and Instability Index that are essential and vital in providing data about the proteins and their properties. Secondary structure analysis predicts that most of them contain only $\alpha$-helices and remaining of them contain mixed structure. The presence of 11 Cys residues in rainbow smelt fish and sea raven fish indicates the presence of disulfide bridges which is also confirmed using CYS_REC and Rasmol tools.

\section{References}

1. Sivakumar K 2005 Adv. BioTech. IV 27

2. Sivakumar K, Balaji S and Gangaradhakrishnan BioChemistry: An Indian Journal (in press)

3. Sivakumar K 2006 Adv. BioTech. IV 18

4. King-Hwa Ling, Shu-San Loo, Rozita Rosli, Mariana Nor Shamsudin, Rahmah Mohamed and Kiew-Lian Wan 2007 Silico Biol. 70011

5. Chitta Suresh Kumar, Anuradha C M, Venkata Rao K and Venkateswara Swamy K 2005 Int. J. Genomics Proteomics 21

6. Yuri F, Bogdanov, Sergei Y, Dadashev and Tatiana M Grishaeva 2003 Silico Biol. 30015

7. Courtney E Garry and Robert F Garry 2004 Theor. Biol. Med. Model. 110

8. Rachel E Bell and Nir Ben-Tal 2003 Comp. Funct. Genom. 4420

9. Raymond J A and DeVries A L 1977 Proc. Natl. Acad. Sci. USA 742589

10. Peter L Davies and Choy L Hew 1990 The FASEB J. 42460

11. Knight C A, DeVries A L and Oolman L D 1984 Nature (London) 308295

12. Garth L, Fetcher, Sally V Goddard and Yaling Wu 1999 Chemtech. 3017

13. Chao H, Davies P L and Carpenter J F 1996 J. Exp. Biol. Sep. 1992071

14. Parody-Morreale A, Murphy K P, Di Cera E, Fall R, DeVries A L and Gill S J 1988 Nature (London) 333 782

15. Steffen P, Graether Carolyn M Slupsky Peter L, Davies and Brian D Sykes 2001 Biophys. J. 811677

16. Pranav Dalal and Frank D Sonnichsen 2000 J. Chem. Inf. Comput. Sci. 401276

17. Li Tong, Qingsong Lin, Raymond Wong. W K, Asma Ali, Daniel Lim, Wing L Sung, Choy L Hew and Danie S C Yang 2000 Protein expression and purification 18175 
18. Wilkins S P, Bluma A J, Burkepilea D E, Rutland T J Wierzbicki A, Kelly M and Hamanna M T 2002 CMLS, Cell. Mol. Life Sci. 592210

19. Boeckmann B, Bairoch A, Apweiler R, Blatter M-C, Estreicher A, Gasteiger E, Martin M J, Michoud K, O’Donovan C, Phan I, Pilbout S and Schneider M 200, Nucl. Acids Res. 31365

20. CLC bio., 2006. CLC free Workbench. http://www. clcbio.com/index.php?id=28, (27/10/2006)

21. Gill S C and Von Hippel P H 1989 Anal. Biochem. 182319

22. Bachmair A, Finley D and Varshavsky A 1986 Science 234179

23. Gonda D K, Bachmair A, Wunning I, Tobias J W, Lane W S and Varshavsky A 1989 J. Biol. Chem. 264 16700

24. Tobias J W, Shrader T E, Rocap G and Varshavsky A 1991 Science 2541374

25. Ciechanover A and Schwartz A L 1989 Trends Biochem. Sci. 14483

26. Guruprasad K, Reddy B V B and Pandit M W 1990 Prot. Eng. 4155
27. Ikai A 1980 J. Biochem. 881895

28. Kyte J and Doolittle R F 1982 J. Mol. Biol. 157105

29. Combet C, Blanchet C, Geourjon C and Deléage G 2000 TIBS 25 291, 147

30. Eisenhaber F, Imperiale F, Argos P and Froemmel C 1996 Proteins Struct. Funct. Design 25157

31. Takatsugu Hirokawa, Seah Boon-Chieng and Shigeki Mitaku 1998 Bioinform. Appl. Note 14378

32. Ramachandran G N and Sasiskharan V 1968 Adv. Prot. Chem. 23283

33. CYS_REC. http://sun1.softberry.com/berry.phtml?topic= cys_rec\&group=help \&subgroup=propt. $(27 / 10 / 2006)$

34. Lambert C, Leonard N, De Bolle X and Depiereux E 2002 Bioinformatics 181250

35. Lovell. S C, Davis I W, Arendall III W B, de Bakker P I W, Word J M, Prisant M G, Richardson J S and Richardson D C 2002 Proteins: Structure, Function \& Genetics $\mathbf{5 0} 437$

36. Cristobal S, Zemla A, Fischer D, Rychlewski L and Elofsson A 2001 BMC Bioinformatics 25

37. Ilya N Shindyalov and Philip E Bourne 2001 Nucl. Acids Res. 29228 